\title{
NEW RESEARCHES IN STEEL METALLURGY*
}

\author{
By DR. W. H. Hatfield, F.R.S., \\ Director of the Brown-Firth Research Laboratories, Sheffield
}

$\mathrm{R}$ ESEARCH in steel metallurgy is directed in the main to three principal aspects: (a) elucidation and improvement of the processes of steel manufacture and manipulation; $(b)$ investigation of the properties of steel under variable conditions approximating to those of service; and $(c)$ exploration of the influence of added elements and of the effect of heat treatment in advantageously modifying the properties of steel

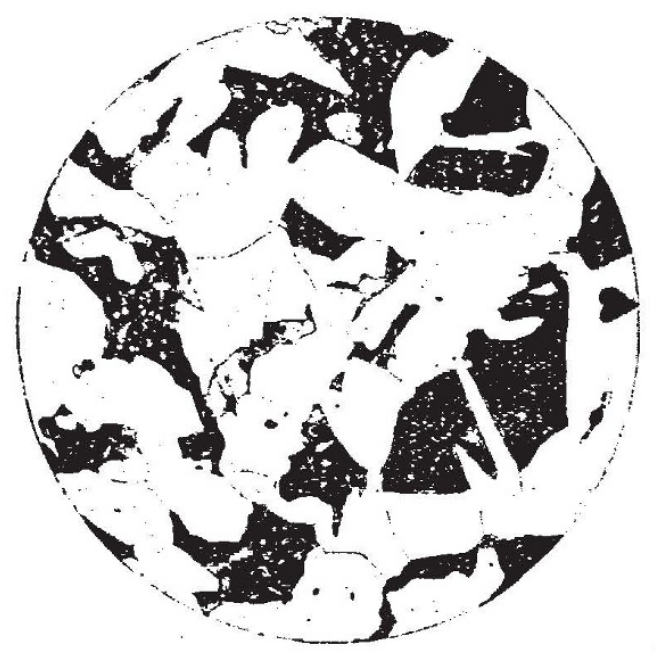

Fig. 1.

Structure of Marine craNkshaft, $\times 100$ (left); ANd aEro ENGINe conNecting-rod, $\times 500$.

and producing those best required under $(b)$. It can in truth be said that great progress has taken place under each heading of late years.

The progress of steel metallurgy is perhaps typified at one of its industrial maxima in the steels produced for the aero engine. Enterprising and imaginative engineers like Dr. Fedden with his engine derelopments must, indeed, demand more and more of us in strength and reliability

Table 1. Mechaxical properties of typical aero conNectisg. ROD AND WARINE CRASKSHAFT

\begin{tabular}{|l|c|c|}
\hline & $\begin{array}{c}\text { Aero } \\
\text { connecting-rod }\end{array}$ & $\begin{array}{c}\text { Mrarine } \\
\text { crankshaft }\end{array}$ \\
\hline Yield point (tons/sq. inch) & 99 & $15 \cdot 8$ \\
Max. stress (tons/sq. inch) & 112 & $31 \cdot 0$ \\
Elongation (per cent) & 14 & 32 \\
Reduction of area (per cent) & 42 & 50 \\
Irod impact (ft. lb.) & 28 to 32 & 12 to 15 \\
Fatigue limit (tons/sq. inch) & \pm 48 & \pm 14 \\
\hline
\end{tabular}

- From a Friday evening discourse delivered at the Royal Institution on March 17 of materials, and such demands, as I hope I shall be able to show, have drawn us along from one development to another. It is instructive, for example, to compare the composition, microstruc. ture, and properties of a marine engine crankshaft made from ductile Siemens Martin steel, with a modern aero engine connecting-rod made from alloy steel produced in the electric furnace (Fig. 1 and Table 1). Of course the former is a massive

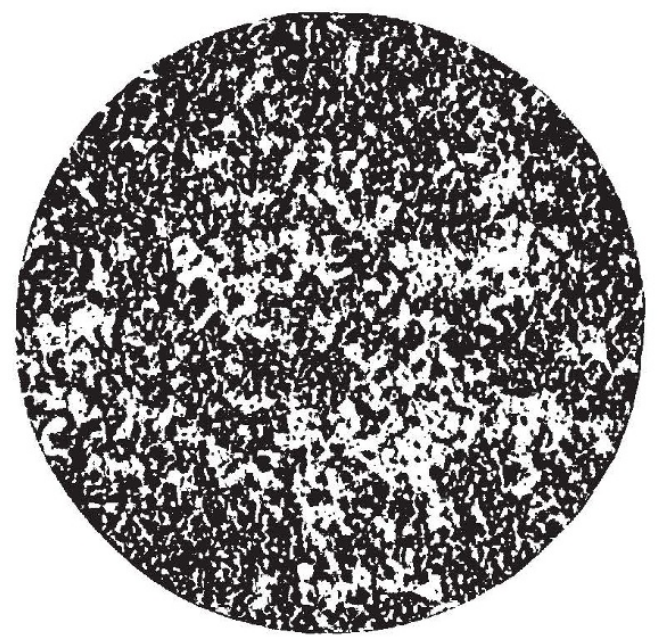

structure, not highly stressed, whilst the latter is small and light in construction and very highly stressed.

\section{Manufacture and Manipulation}

It will be appreciated that in studying the refining process the physical chemistry relates to very high temperatures. What are the actual reactions between the liquid metal and the superimposed liquid slag? The refined liquid steel is poured into the mould and freezes. Liquid steel being a solution of various elements or their compounds in iron, which by differential freezing solidifies into a crystalline mass quite heterogeneous in character, one of the principal studies of recent years has been the determination of the nature and degree of this heterogeneity as affected by process, composition and conditions of casting. Ingots of various sizes and shapes in various 
steels have been sectioned and the implications of this heterogeneity in the forged or rolled product have been studied in order that the most suitable ingot as regards process, form and composition can be selected.

As a result of the reactions of the steel-making process, the liquid steel contains disseminated through it small quantities of oxides of silicon, iron, manganese and other elements, but during the cooling and freezing process these oxides coalesce and orientate themselves in well-defined design; along with these oxides are sulphides resulting from the sulphur content of the steel. Such oxides and sulphides form weakness transversely to the direction of forging and rolling, and any mitigation of the trouble by reduction of the oxide and sulphide content is much to be encouraged.

This problem is steadily yielding to inquiry and experiment, although the experimental difficulties are great. The compounds in equilibrium or indeed in existence at $1600^{\circ} \mathrm{C}$. in the liquid phases are not necessarily those encountered at $15^{\circ} \mathrm{C}$. Solubilities are different, and hence, for example, the difficulties of studying the solubility of gases. It is important to know the oxygen content and its condition in the liquid steel; one great step forward has been the development of the vacuum fusion method of determining the total oxygen in the final steel, but we have not as yet quite mastered the technique of determining the form in which the oxygen occurs. The nitrogen and hydrogen contents of steel are also having much attention, and these, particularly the hydrogen content, may prove of consequence.

In small masses, modern technique gives very good results as regards homogencity, but if you pour 100 tons or 200 tons of liquid steel into a mould and allow it to freeze, the differential freezing produces a heterogeneity of a more serious order which is clearly transmitted in the structure of the final forging. If a large ingot is sectioned along its axis and the plane exposed is studied for variable composition and segregates, the nature of the result of the inquiry is indicated in Fig. 2.

Whether the ingot be small or very large, it has to be heated to a sufficiently high temperature for forging and/or rolling. Also steel in varying mass has to be reheated and cooled in the heattreatment processes such as annealing, hardening, tempering and stress-annealing. Thus, much research has of late been devoted to studying temperature gradients within the mass with different rates of heating and cooling, the reason being that temperature gradients produce internal stresses under certain conditions high enough to produce rupture, and when of even much lower order may in part be permanent in character.

\section{Effect of Temperature on the Properties of STEels}

Perhaps one of the most complex studies is that of the changing properties of steel with varying temperature. It is of the utmost importance to the engineer that he should know the stresses the material will withstand under such changing and different conditions. Important steam-raising and power-generating units operate at temperatures up to $500^{\circ} \mathrm{C}$., whilst items such as exhaust valves, superlieater and furnace parts operate at $700^{\circ}$ to more than $1000^{\circ} \mathrm{C}$. On the other hand,

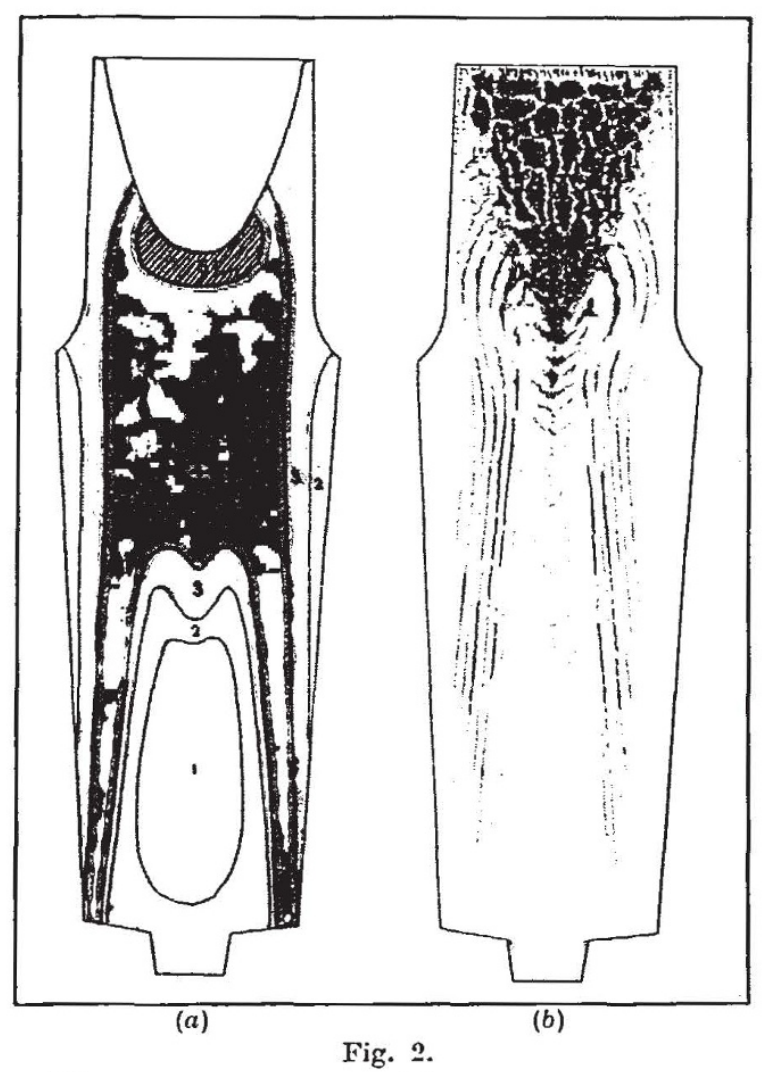

180-TON INGOT SHOWING (a) zONES OF VARTABLE cosrposirion; (b) DISTRIBUTION OF SEGREGATES. (a) The lighter the zones the lower tho percentago of the elements which were in solution in the liquid steel. (b) Streamerz of segregates aro shown.

steels used in aeroplane construction and special engineering must encounter very low temperatures; indeed, for experimental work, steel has been supplied to operate at $-180^{\circ} \mathrm{C}$.

This study includes a knowledge of the properties of steel at ordinary temperature and at the special temperatures after a lapse of time comparable with the later stages in the length of life of the part under service conditions.

To instance the nature of research in this field one must emphasize that, whereas until compara. tively recent years the understanding of tho 
mechanical properties of metals has been based upon rapidly applied stresses at the normal temperature resulting in destruction, as in the case of the well-known tensile, torsion, bending or notched bar impact tests, the experiments to which I am about to refer concern stresses of a known magnitude applied over long periods of time at temperatures well above the normal and in conformity with temperatures of service. Permanence of form and dimensions, except for elastic deformation under service stresses with a practical absence of plastic deformation, is fundamental to the successful operation of much modern mechanism, whereas the rapid destruction tests just referred to provide information of plastic deformation under rapidly applied stresses of sufficient magnitude to cause rupture, which has little bearing upon the problem of safety in design. The data really required concern the range of stress which can be safely carried without producing plastic deformation in excess of previously determined very small permissible values.

Nearly ten years ago I put in hand an experiment which is still proceeding. This experiment consists of placing a strip of steel in tension under a stress of 25 tons per square inch. The material was a cold-worked austenitic steel with a limit of proportionality of $27 \cdot 4$ tons per sq. inch and yield point of 77 tons per sq. inch. Since June 1929 the permanent extension has been nil within the accuracy of measurement applied, namely, a sensitivity of $1 / 40,000$ of an inch and a gauge length of 8 inches. Clearly, if deformation is proceeding, it is at a less rate than $4 \times 10^{-11}$ or $1 / 25,000,000,000$ of an inch per inch per hour, and it may bo claimed that evidence is still lacking of change of dimensions in this case under a stress so high as 25 tons per sq. inch. The temperature in this case is $23^{\circ} \mathrm{C}$. and the data from the ordinary tensile test broken at atmospheric temperature enabled the stress employed to be selected. The experiment now constitutes a creep test over a period of 85,000 hours.

With the introduction of temperature above certain values, this phenomenon of creep becomes a dominating one, and the problem is to determine the stress which will not produce creep or deformation beyond postulated values under the conditions we are considering. The facts differ with different steels for the same ranges of temperature and for different temperatures with the same steel, and therefore only selected experimental data can be given to illustrate the phenomena.

To take the range of steam temperatures and compare the behaviour of two steels, namely, mild carbon steel and a similar steel containing molybdenum, at a temperature of $400^{\circ} \mathrm{C}$., ordinary tensile tests give the following values :

\begin{tabular}{|c|c|c|c|c|}
\hline & $\begin{array}{l}0.5 \% \\
\text { Proof } \\
\text { Stress } \\
\text { (tons/ } \\
\text { sq. in.) }\end{array}$ & $\begin{array}{l}\text { Jax. } \\
\text { Stress } \\
\text { (tons/ } \\
\text { sq. in.) }\end{array}$ & $\begin{array}{l}\text { Elong. } \\
\text { (per cent) }\end{array}$ & $\begin{array}{l}\text { Reduction } \\
\text { of Area } \\
\text { (per cent) }\end{array}$ \\
\hline $\begin{array}{l}\text { Mild steel at } 20^{\circ} \mathrm{C} \text {. } \\
\text { Mölybdënum } 400^{\circ} \mathrm{C} \text {. }\end{array}$ & $\begin{array}{l}20 \cdot 25 \\
16 \cdot 2\end{array}$ & $\begin{array}{l}34 \cdot 1 \\
32 \cdot 54\end{array}$ & $\begin{array}{l}40 \cdot 8 \\
38 \cdot 5\end{array}$ & $\begin{array}{l}64 \cdot 7 \\
62 \cdot 0\end{array}$ \\
\hline stcel at $20^{\circ} \mathrm{C}$. & $\begin{array}{l}23 \cdot 5 \\
20 \cdot 5\end{array}$ & $\begin{array}{l}38 \cdot 0 \\
36 \cdot \frac{7}{7}\end{array}$ & $\begin{array}{l}29 \cdot 0 \\
30 \cdot 0\end{array}$ & $\begin{array}{l}47 \cdot 0 \\
50 \cdot 0\end{array}$ \\
\hline
\end{tabular}

If constant values of stress are applied to these two steels at a temperature of $400^{\circ} \mathrm{C}$. over a period of 1000 hours, and careful determinations made of the effect of the loads, it will be found that deformation proceeds at stresses well below the tensile test yield point. With a stress of 15 tons per square inch the mild steel creeps during the 24 th to $72 \mathrm{nd}$ hour period at a rate of $26 \times 10^{-6}$ inch per inch per hour, and even in the 500-1000 hour period at a rate of $1.1 \times 10^{-6}$; whilst with a stress of 7 tons per square inch creep occurs in the 24th to 72nd hour period at a rate of $1.1 \times 10^{-6}$, and in the 500-1000 hour period at a rate of $6 \times 10^{-8}$. The addition of molybdenum to the other steel enables a stress of 15 tons per square inch to be sustained with a rate of creep of $1.25 \times 10^{-6}$ in the 24th to 72 nd hour period, and so low a rate as $1.4 \times 10^{-7}$ for the $500-1000$ hour period. Thus, it is shown that, by long experiments of this character, the influence of added elements is determined as regards a most important characteristic of the material.

The results of experiments conducted at tem. peratures of $900-1000^{\circ} \mathrm{C}$. over very long periods of time will be of interest. A heat-resisting steel, that is, a steel having the necessary resistance to oxidation as well as some strength at high temperatures, containing carbon 0.21 per cent, nickel 12.32 per cent and chromium 21.09 per cent, was maintained under a load of $280 \mathrm{lb}$. per square inch for the period of 10,000 hours at $900^{\circ} \mathrm{C}$. The load produced an initial rate of creep which diminished with time to a value of movement which became constant after about 2000 hours. Over the whole period of 10,000 hours the material permanently extended in length about 0.50 per cent.

The microstructure in Fig. $3(a)$ is that of the test piece as not exposed to the high temperature, whilst $(b)$ illustrates the change in structure after. the 10,000 hours exposure at $900^{\circ} \mathrm{C}$. to the atmosphere; (c) illustrates the structure up to the surface, and it is seen that oxidation has taken place, but must have been slowed up by the protective oxide formed during the exposure.

This experiment shows that with this steel under these conditions the rate of creep does slow up to a constant minimum rate, but that, even so, creep or deformation under the applied stress then 
continues at that rate. Similar experiments indicate, however, that the course of this particular experiment is not always repeated.

Such long time tests are quite impractical as a means of comparing the creep properties of large numbers of alloys. This was foreseen many years ago, and a short time test, extending over a period of only three days, was devised, which is applicable to the whole range of temperature from $300^{\circ} \mathrm{C}$. to $1000^{\circ} \mathrm{C}$., and has been used on an extensive scale in the testing of many alloys. The applied stress is permitted to produce deformation over the first 24 hours not exceeding 0.5 per cent of the gauge length, but during the next 48 hours no further change in dimensions shall take place within the accuracy of measurement, which is to
Table 2. Effect of compositios cpos 'Creep' Characteristics OF STEELS

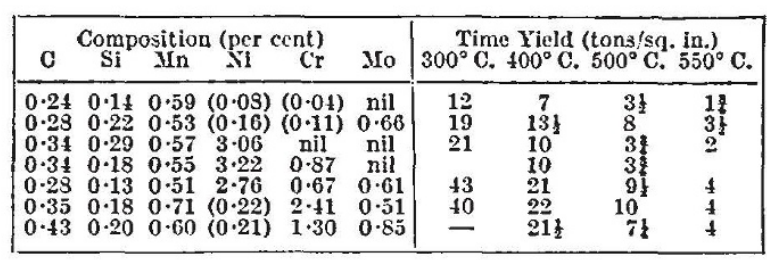

steam practice range of temperatures, whilst Table 3 gives comparative data for a number of steels within the higher range of temperature.

One important line of investigation concerns the effect of exposure to temperature for a long time upon the mechanical properties of the steels.

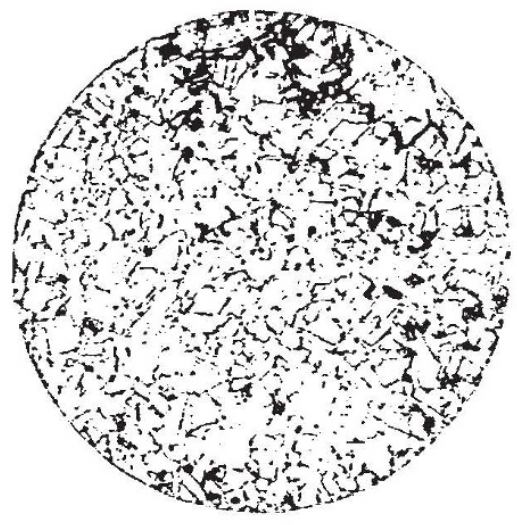

(a)

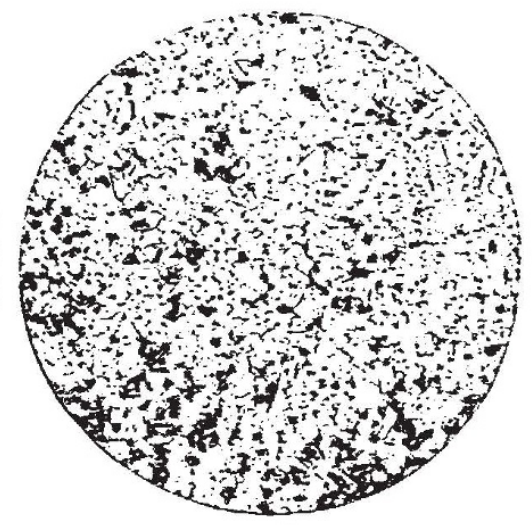

(b)

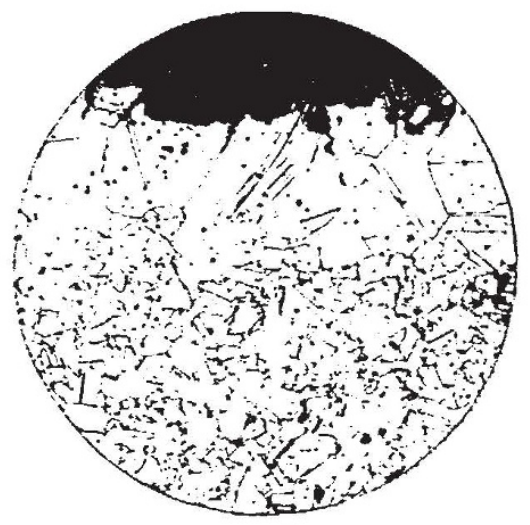

(c)

Fig. 3.

EFfEct of pRoLoNged exposune at $900^{\circ} \mathrm{C}$. ON MrCROSTRUCTURE OF A HEAT-RESISTING STEEL. (a) Before exposure ; (b) after exposure for 10,000 hours; (c) edge after exposure for 10,000 hours. All $\times 100$.

$1 / 40,000$ inch. On a gauge length of two inches, this is approximately equivalent to one millionth of an inch per inch per hour. The maximum stress not producing a deformation in excess of that so postulated has been named the time yield, and produces data which can be interpreted usefully with the assistance of data for longer period and more sensitive experiments. Table 2 schedules results on different steels obtained within the
Extremely important mechanical units have to operate for a life of many years at elevated temperatures, and owners are not very free in scrapping valuable parts so that tests can be made to see whether the mechanical properties of the materials are being maintained.

Some time ago we installed substantial furnaces for long-time experiments of this character and have many steels exposed, for example, at $400^{\circ} \mathrm{C}$.,

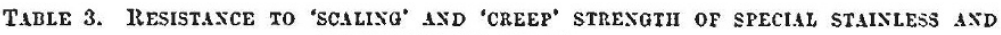
HEAT-RESISTING STEELS.

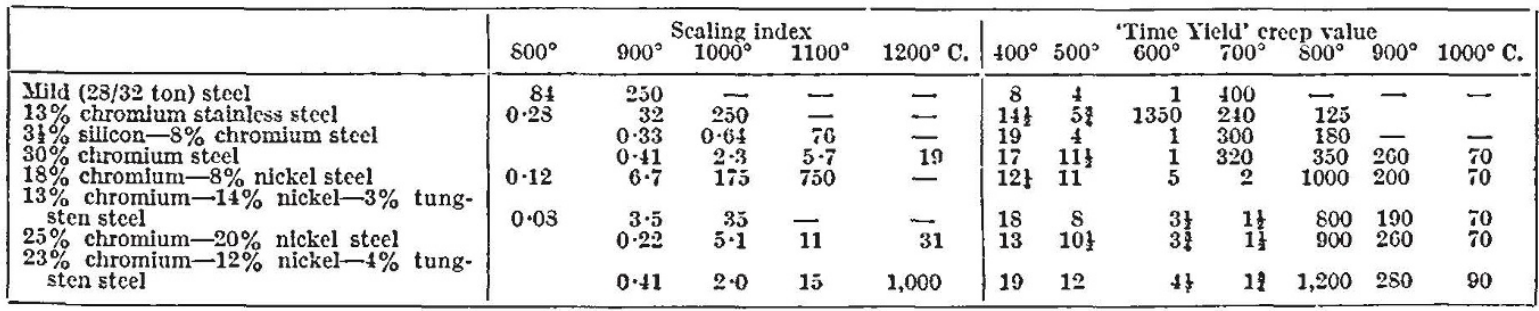

"Scaling" index expressed in milligrams per sq. cm. increase in weight.

"Creep" strength expressed in tons/sq. inch above 1 ton and in lb./sq. inch below. 
$450^{\circ} \mathrm{C}$. and $500^{\circ} \mathrm{C}$. Each test piece is substantial in size and enables a very complete study of the material to be made. Samples of a particular steel are taken out after one month, six months, twelve months, and so on, and already valuable data have been derived.

We have already found that some steels maintain their properties; others, whilst maintaining their tensile test values, offer less resistance to notched bar impact fracture, and others by a type of precipitation proceeding even after twelve months exposure have a progressively increasing strength and a decreasing ductility. Tests done at normal temperatures after exposure are not an adequate indication of the actual properties at the elevated temperature at which they have been exposed, and therefore since the temperatures selected simulate service conditions, the mechanical tests are also being performed at these temperatures. In the main, the experiments to date indicate a more ductile condition at the temperature than in the cold.

\section{Effects of Alloying Other Elements}

The metallurgical processes in industrial use produce in bulk an impure iron, that is, mild steel, which is iron with a residual carbon content of 0.10-0.20 per cent and a residual manganese content of $0 \cdot 40-0.8$ per cent, having - very useful mechanical and fabrication qualities for structural purposes, marine engineering and many other purposes. By increasing the carbon content the strength of the steel is increased and its ductility decreased, but qualities suitable for rails, tyres or even tools are so prepared.

The multiplicity of alloys which it would bo necessary to make to exploit thoroughly the possibilities of the influence of added elements is obvious, and, therefore, it is clear that only the fringe of the subject has yet been explored. Mfuch success, however, has been achieved.

High tensile steels are available through the influence of small quantities of added elements, but the more outstanding advances relate to the influence of larger additions of the special elements.

A high percentage of nickel produces a steel with a very low coefficient of expansion, whilst certain percentages of nickel, manganese and chromium enable steel to be produced with a high coefficient of expansion comparable with that of the aluminium alloys.

High percentages of cobalt, or of nickel and aluminium, enable permanent magnets of amazingly high coercive force to be produced. The presence of small quantities of chromium and aluminium enable hardened surfaces to be produced, by the influence of ammonia at temperatures as low as $500^{\circ}-550^{\circ} \mathrm{C}$.
High manganese content produces a steel of excellent wearing properties under abrasion, whilst high chromium or high chromium and nickel contents produce a range of steels which are rust- and acid-resisting. Add to the last category other special elements and the interesting heat-resisting steels are produced which not only resist scaling at high temperatures, but have also considerable strength under such conditions.

Perhaps the most outstanding achievement of recent times is the development of the rustless and heat-resisting steel metallurgy. Brearloy in 1913 had shown that a stainless knife could be made by hardening and tempering a steel containing 13 per cent of chromium. This led to the search for steel which was rustless in the ductile condition, and so the 18 per cent chromium, 8 per cent nickel, and the 12 per cent chromium, 12 per cent nickel, and other combinations were produced. Such steels are indeed stainless under normal conditions, and form the basis now of a great industry.

Ono is invariably asked, Why are the rustless steels rustless? The answer is, that they are cases of passivity, induced by composition and normal environment in the production of a passive external film. This is in part proved by the fact that under certain conditions local corrosion will take place oven with so defined rustless steels, as a result of shielding action. Shielding action is the effect of a deposit of material resting on the surface of the steel, which by its presence partially or completely prevents free access of oxygen to this surface of the steel, and thereby retards or prevents the repair of any minor breakdown of passivity. It is obviously necessary, in order that corrosion should develop, that the shielding agent should not entirely prevent access of the corroding solution. Such a conception is in line with the explanation which Faraday advanced in 1836 in explanation of the chemically induced passivity in the case of ordinary iron surfaces; he visualized that "the surface of the iron is oxidized on the superficial particles of the metal and in such relation to the oxygen of the electrolyte as to be equivalent to oxidation." It was left to Dr. Ulick Evans to isolate such passive films.

The following experiment has reference to the gradual and visible thickening of this passive film under rather special conditions with time. In December 1924 (more than fourteen years ago), a cylinder of plain 18 per cent chromium, 8 per cent nickel steel was placed in a bottle of nitric acid of strength slightly higher than $1.20 \mathrm{sp}$. gr. After a year or two a clouding of the surface was noticed, and, accordingly, in June 1928 a second cylinder was immersed under similar conditions; again the same effect was noticed with the passing of time. In 
June 1931 a further cylinder followed. These three cylinders have now been exposed for periods of 14 years, $10 \frac{1}{2}$ years and $7 \frac{1}{2}$ years respectively. The first is covered with a dark brown film, the second with a straw-coloured film, whilst the third as yet shows only a slight dulling of the surface. This evidently slower rate of film thickening, in the case of the third eylinder, may be due to its having a mirror finish as compared with a fine emery finish in the case of the other two cylinders.

The solutions were examined in August 1938, and from these figures the weight of iron and of chromium dissolved from the cylinders was calculated, and it was found that there was a deficiency of chromium in relation to the iron when the relative proportions in which these two elements were present in the steel were taken into account. It was then assumed that this missing chromium is present in the form of $\mathrm{Cr}_{2} \mathrm{O}_{3}$ in the films on the surfaces of the cylinders, and the amounts were calculated.

It is interesting to note that the calculated thicknesses of the films on the first two cylinders are not far removed from the value of about $4 \times 10^{-8}$ which is obtained from the work of several investigators for the thickness of films giving a similar coloration. In the case of the third cylinder, the calculated film thickness is less than the minimum thickness required to give a definite coloration.

It was quite accidentally discovered that a oylinder of 13 per cent chromium steel which is apparently not affected by nitric acid but is soluble in sulphuric acid, became passive for long periods in sulphuric acid after immersion for a period in nitric acid. This observation was made some fifteen years ago and before we had obtained the interesting data from the three cylinders of 18/8 material. Evidenco indicates that the corrosion-resisting properties of the rustless steels are due to the chromium facilitating the spontaneous production of a protecting film of the necessary characteristics for resistance, which film if damaged is spontaneously renewed.

Experimenting upon the basis of the rustless steel compositions, it has been found that by modifying the chromium and nickel and also by adding other elements such as tungsten, molyb. denum, cobalt or titanium, steels are produced which maintain a reasonably protective film at temperatures even in excess of $1000^{\circ} \mathrm{C}$., and also have useful strength.

\section{THE ROYAL AGRICULTURAL SHOW}

\section{By Prof W. B. Brierley}

$\mathrm{I}^{\mathrm{N}}$ English agriculture the "Royal Show" is the peak of the year, and the occasion in 1939 is of special significance as it marks the centenary of the Royal Agricultural Society of England. It is fitting, therefore, that the Show should be held during July 4-8 in the Royal Park of Windsor, and that the University of Reading, which increasingly plays a leading part in agricultural education and research, should have been invited to accept responsibility for the scientific exhibit. The exhibition in the building devoted to education, research and marketing was arranged by the Faculty of Agriculture and Horticulture of the University (including the National Institute for Research in Dairying and the British Dairy Institute) with additional exhibits by the counties of Buckingham (acting in co-operation with the Buckinghamshire Producers) and Northampton.

For many years, the scientific exhibit at the Royal Show has been of very high calibre, and this is all the more creditable when it is remem. bered that agricultural teaching does not lend itself to exhibition, and that agricultural research is of a somewhat plodding nature and that it possesses none of the more spectacular qualities of research in many other branches of science. Each year, however, it has become increasingly difficult to improve on the interest of former exhibits or to vary them in kind, and for the special occasion of a centenary show the young University of Reading was faced with an exceptionally difficult task. It achieved a notable success due, primarily, to two facts: first, the entire exhibit was arranged on the central theme of the progress in agricultural research and its application to practice during the last hundred years, and, secondly, the individual exhibits were merged in a common decorative scheme designed and produced by the School of Art of the University of Reading. The many scientific exhibits were excellent, but it was the happy marriage of science with art which remains the outstanding impression left by the scientific building.

In any scientific exhibition the benches are occupied by specimens, instruments, etc., but it is always difficult to know what to do with the wall 